\title{
Regional Evidence of Global Warming
}

\author{
Jonas Bhend
}

\begin{abstract}
This chapter assesses to what extent the factors causing global warming affect the Baltic Sea area. Summertime near-surface warming in northern Europe exceeds natural internal variability of the climate system, and the observed warming cannot be explained without human influence. Regional changes in extreme temperatures, growing-season length and timing of the onset of spring are consistent with the large-scale signal of a human influence (mainly greenhouse gases). Shifts in large-scale circulation in the Northern Hemisphere and precipitation changes in northern Europe and the Arctic have been detected to exceed natural internal variability, but the climate models used to assess these quantities seem to underestimate the observed changes. To what extent this discrepancy between simulated and observed changes also affects the attribution of regional warming to human influence is still a matter of debate. Other aspects of regional climate change including changes in storminess, snow properties, run-off and the changing physical properties of the Baltic Sea have not been formally attributed to human influence yet.
\end{abstract}

\section{Keywords}

Regional climate change $\cdot$ Detection and attribution

\subsection{Introduction}

This chapter assesses how the factors causing global warming (mainly anthropogenic greenhouse gases) affect climate in the Baltic Sea area. In contrast to the following chapters on the effect of anthropogenic aerosols (Chap. 24) and land-use and land-cover changes (Chap. 25), this chapter focuses on globally uniform or at least large-scale forcing including changes in greenhouse gases, solar irradiance and stratospheric volcanic aerosols.

To demonstrate an external influence on the observed climate change, the concept of detection and attribution is often used. Formal detection and attribution imply (i) the demonstration that the recent observed change is different

J. Bhend $(\square)$

Federal Office of Meteorology and Climatology,

MeteoSwiss, Zurich, Switzerland

e-mail: jonas.bhend@meteoswiss.ch from natural internal variability - the detection - and (ii) the comparison of different combinations of external forcing and assessment of their relative contribution in explaining the detected change - the attribution (see also Annex 1). Such a framework has been successfully applied at the global and continental scale to detect and attribute anthropogenic nearsurface and upper-level warming, as well as large-scale changes in other climatic parameters (Hegerl et al. 2007a). At the regional scale, however, there are only very few formal detection and attribution studies available (see Stott et al. 2010 for a review of recent advances).

Climate change detection and attribution at the regional scale is complicated by various factors. First, variability increases with decreasing area of aggregation, that is the influence of small-scale phenomena does not average out. This generally leads to a decrease in the signal-to-noise ratio of externally forced changes and thus reduces the detectability of regional climate change (Stott 2003; Zwiers and Zhang 2003). Second, model biases play a more important 
role at the regional scale as model performance depends on the spatial resolution of quantities under analysis (Masson and Knutti 2011). This influences our ability to detect and attribute changes at the regional scale as the simulations of recent change and variability deteriorate at smaller spatial scales. Third, forcing mechanisms that are less well understood such as changes in anthropogenic aerosols or that are thought to have a negligible effect on recent global warming such as land-cover changes may be relatively more important at the regional scale (Stott et al. 2010, see Chaps. 24 and 25 for further discussion). In addition, regional detection and attribution in northern Europe seems to be especially difficult compared with other subcontinental regions worldwide. Owing to the position of northern European landmasses at the end of the North Atlantic storm track and due to the complex land-sea distribution, interannual variability in most climatic parameters is very strong, thus masking external influences (see Fig. 9.12 in Hegerl et al. 2007a). In these cases, all that is possible is to assess whether the simulated response to external forcing is consistent with the observed change.

\subsection{Causes of Change in Temperature}

\subsubsection{Mean Near-Surface Temperature}

A cascade of evidence from global to subcontinental scales illustrates the anthropogenic influence on recent observed warming (see also Chap. 4, Sect. 4.4). The human influence on global warming (Hegerl et al. 1997), continental warming in Europe (Stott 2003; Christidis et al. 2010a), northern Europe in all seasons combined (Bhend 2010) and warming in northern Europe in summer (Jones et al. 2008) has been successfully detected. Jones et al. (2008) further concluded that anthropogenic warming has already increased the likelihood of occurrence for very warm summers in northern Europe. Using occurrence probabilities as the detection variable, Stott et al. (2011) found mixed evidence of an anthropogenic effect on the frequency of very warm seasons with a detectable anthropogenic influence in spring (MAM) and autumn (SON) and no detectable natural influence. In summer (JJA) and winter (DJF), the detectability of external influences depends on the climate model used.

Zorita et al. (2008) used an alternative approach to the detection problem by computing the likelihood of clusters of record warm years in a stationary climate. Depending on the model for long-term memory of regional temperature time series, they found very low probability of the observed cluster of record-breaking warm years in northern Europe during the past decades. Their approach, however, does not explicitly address potential causes of the warming needed to explain the recent cluster of record-breaking years.
The influence of external forcing is more difficult to detect at smaller spatial scales (Stott and Tett 1998; Zwiers and Zhang 2003). At the grid-box scale of global climate models (approx. $300 \times 300 \mathrm{~km}$ ), the observed warming up to 2002 in the Baltic Sea region is not significantly different from changes due to internal variability alone, and therefore, an anthropogenic influence is not detectable (Karoly and $\mathrm{Wu}$ 2005). However, the simulated warming in the Baltic Sea area is consistent with the observed warming when anthropogenic forcing (changes in greenhouse gas and sulphate concentrations) is included in the simulations with three different global climate models (the GFDL R30, HadCM2 and PCM models, Karoly and $\mathrm{Wu} 2005$ ). The observed warming is also found to be consistent with anthropogenic signals derived from simulations with a coupled regional atmosphere-ocean model (Bhend and von Storch 2009), whereas van Oldenborgh et al. (2009) found significant differences between observed and simulated warming in spring (MAM) using global climate models. They identified the misrepresentation in circulation and snow cover changes as the main reason for the underestimation of warming in spring in global climate models. A recent study by Flanner et al. (2009) suggested that the underestimation of springtime warming at mid-latitudes is due to the lack of carbonaceous aerosols in climate model simulations. These particles darken the snow surface and thus increase the albedo, leading to a warming especially in spring when the snow surface is exposed to intense solar radiation (see Chap. 24 for discussion of the local effects of aerosols). Whereas this forcing mechanism was not included in previous climate model simulations, most models submitted to the World Climate Research Programmes's CMIP5 (Taylor et al. 2011) database include carbonaceous aerosols, which implies that the role of carbonaceous aerosols may be addressed in future attribution studies.

In addition to analyses using local information only (e.g. observed and simulated data for the Baltic Sea area), evidence for a regional anthropogenic warming is also found in formal detection and attribution studies using global constraints (Christidis et al. 2010b). Pooling climate data information across the globe helps to significantly increase the signal-to-noise ratio of externally forced changes. The additional information available when carrying out analyses simultaneously for multiple regions further helps to distinguish responses to different forcings that may be indistinguishable in individual regions. Using such an approach, Christidis et al. (2010b) detected and attributed human influence on the observed warming in northern Europe from 1950 to 1997 (see Fig. 23.1). The authors also computed the fraction of attributable risk (FAR, Stott et al. 2004) of the observed warming in northern Europe. FAR is a measure of the change in likelihood of a given warming in a world with human influence compared to the likelihood of such a 


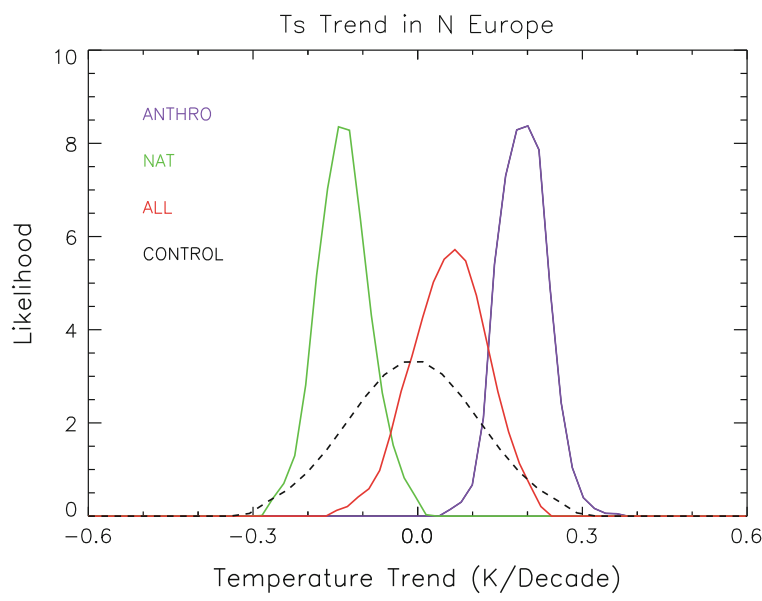

Fig. 23.1 Distribution of attributable trends in near-surface temperature in northern Europe (NEU) from 1950 to 1997 based on optimal fingerprint analysis using global constraints (reproduced from Christidis et al. 2010b). Shown are the trends due to anthropogenic forcing (ANT, purple line), natural forcing (NAT, green line) and all forcings (ALL, red line). The black dashed line denotes the distribution of trends due to internal variability as estimated from control simulations (CONTROL). The observed trend of $0.056{ }^{\circ} \mathrm{C}$ per decade (not shown) is consistent with the all-forcing signal (ALL, red line)

warming in a hypothetical world free of anthropogenic influence. The authors concluded that the likelihood for a warming from 1950 to 1997 in northern Europe more than doubled with a central estimate of a fivefold increase due to human influence. In a world without human influence, a cooling of $-0.15{ }^{\circ} \mathrm{C}$ per decade could be expected in northern Europe mainly due to the cooling effect of volcanic eruptions during that time.

Min and Hense (2007a) investigated evidence for competing forcing hypotheses in a Bayesian framework. The authors concluded that the combination of anthropogenic and natural forcing better explains the observed change in annual and seasonal temperature in Europe from 1900 to 1999 than any of the forcings separately. They found strong evidence for a forced change over natural internal variability alone (detection) in the periods 1900-1999 and 1950-1999 but less so at the beginning of the twentieth century. Treating the detection problem in a Bayesian framework allowed the authors to also quantify the effects of different prior beliefs. These prior beliefs reflect our understanding of the problem before analysing the data. In the analysis of Min and Hense (2007a), only a strong prior belief that recent climate change is due to natural internal variability would favour this hypothesis over others. Compared to other continental-scale regions, the observational evidence of a man-made warming in Europe is less decisive. Min and Hense (2007b) extended the analysis to subcontinental regions and using different models individually as opposed to using the multi-model mean.

Christidis et al. (2007) found a detectable change in growing-season length, the onset of spring and a marginally detectable change in the end of the growing season in autumn for Europe. Moreover, Gillett et al. (2008) found a detectable anthropogenic influence on Arctic warming. Their study region encompasses the very northern part of the Baltic Sea catchment but includes land temperature measurements on all continents and islands north of $65^{\circ} \mathrm{N}$.

Another source of evidence for anthropogenic warming in northern Europe stems from palaeorecords. Hegerl et al. (2011) investigated the effect of external forcing on European temperature using reconstructed temperature back to AD 1500. They detected external influences in all seasons, with the response to external forcing explaining about $30 \%$ of the interdecadal variance.

\subsubsection{Temperature Extremes}

Climate change not only affects the mean climate but also affects all properties of the distribution including the frequency, intensity and spatio-temporal pattern of extreme events. Extreme events are rare, and thus, fewer data are available to make inference about extreme events and their changes. Attributing causes of change in extreme events is thus generally more difficult than for changes in mean climate. Methods involving very large ensembles of climate model simulations are being developed to quantify the human contribution to individual extreme events such as the autumn 2000 floods in the UK (Pall et al. 2011). In contrast, changes in moderately extreme events such as the coldest night or hottest day in any given year can be attributed using standard approaches.

Kiktev et al. (2003) found positive trends in warm nights and frost days for the Baltic Sea area, although significant only for parts of the area (see also Chap. 4, Sect. 4.4). They also found better agreement with simulated trends in those temperature extreme indices when atmosphere-only general circulation model (GCM) simulations include anthropogenic forcing. Morak et al. (2011) got mixed results for detectability of the observed change in warm nights in northern Europe, whereas this change was robustly detectable in other regions. These findings are corroborated by Zwiers et al. (2010) who obtained a detectable anthropogenic signal on changes in waiting times of long return-period extremes (20year return values in the 1960s) of daily temperature in northern Europe. A combined anthropogenic and natural influence is only detectable for the warmest night per year (see Fig. 23.2). Formal attribution of the changes in temperature extremes to natural and/or anthropogenic causes is not yet fully achieved, but the consistency of observed changes with both all-forcing and anthropogenic-only forcing simulations indicates that changes in extreme events may be attributed to human influence. Zwiers et al. (2010) further estimated the attributable change in waiting times for the 


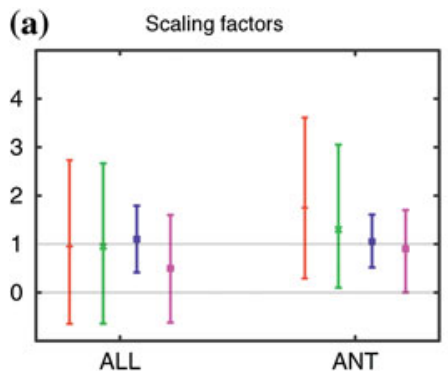

Fig. 23.2 a Scaling factors for annual temperature extremes and b estimated waiting times of 1960s 20 -year return values in the 1990s. The colours refer to extreme value distributions fitted to different annual temperature extremes, namely (per year) the coldest night in red, the coldest day in green, the warmest night in blue and the hottest day in

different temperature extremes. They found that cold events that used to occur on average every 20 years in the 1960s were roughly twice as rare in the 1990s due to human influence. Similarly, waiting times for hot extremes are approximately halved; that is, an extremely hot day with a probability of occurrence of once in 20 years in the 1960s is expected to occur on average once in 10 years in the 1990s due to human influence.

Christidis et al. (2005) found detectable changes in the warmest nights and coldest nights and days of the year globally. Using a more sophisticated measure of extremes, Christidis et al. (2011) also detected an anthropogenic influence on changes in the hottest day of the year. Regional detail of the changes in the warmest nights is given by Christidis et al. (2010b); their analysis, however, identified a dependence of the first-guess anthropogenic signal in the Baltic Sea area on the model used. This illustrates the importance of taking intermodel differences such as differences in the regional response to external forcing into account in regional detection and attribution analyses.

\subsubsection{Potential Influence of Circulation Changes on the Detectability of Warming}

A major caveat of attributing causes for the observed warming in northern Europe is the poor understanding of the possible influence of changes in Northern Hemisphere circulation (Gillett 2005). It is known that modes of natural variability such as the North Atlantic Oscillation (NAO) have a strong influence on temperature in the Baltic Sea region (e.g. Hurrell et al. 2003, Chap. 4, Box 4.1 and Sect. 23.3.1), but the uncertainties in model-simulated circulation and the lack of understanding in the related key processes represent a major source of uncertainty in model predictions over Europe (Woollings 2010).

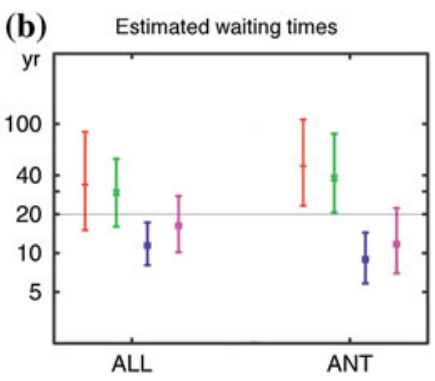

purple. The symbols indicate the central estimate, and the bars denote the $90 \%$ confidence interval. Detection of an external influence is claimed at the $10 \%$ level if the confidence interval around the scaling in (a) does not include zero (reproduced from Zwiers et al. 2010)

Gillett et al. (2000) investigated the effect of changes in the Arctic Oscillation (AO) on detection results and found that for Northern Hemisphere temperatures, the exclusion of the AO-related temperature variability has a negligible effect on the outcome of an optimal detection analysis. These findings are corroborated by $\mathrm{Wu}$ and Karoly (2007), who found significant trends in the observed warming time series even after removing warming related to changes in circulation. For the Baltic Sea area, however, exclusion of warming related to circulation changes reduces the significance, thus indicating that model biases in representing circulation changes may more strongly affect regional attribution studies. In addition, the follow-up study of $\mathrm{Wu}$ (2010) illustrated that while the above results may hold for seasonal mean daily mean temperatures, modes of atmospheric variability have a strong influence on trends in seasonal mean daily maximum and minimum temperature in northern Europe in winter (JFM). The significant observed warming in these variables from 1951 to 2000 can be explained by changes in the leading modes of circulation variability in the Northern Hemisphere alone.

\subsection{Causes of Change in Circulation and the Hydrological Cycle}

\subsubsection{Large-Scale Circulation}

Northern European climate is strongly related to the NAO (Hurrell et al. 2003). Changes in this mode of atmospheric variability have been shown to not be well simulated by present-day climate models (Gillett 2005; Miller et al. 2006). The sign of the simulated change generally corresponds with the observed change, but the simulations seem to underestimate the magnitude of the observed change.

Gillett et al. (2005) detected an external influence on the observed global sea level pressure (SLP) changes in winter 
(DJF) and Wang et al. (2009) on North Atlantic SLP changes in winter (JFM). The fingerprint used in Gillett et al. (2005) featured positive trends in the southern North Atlantic and negative trends around Iceland, thus representing an increase in the NAO index. In a more recent study, Gillett and Stott (2009) were able to attribute zonally averaged SLP changes to anthropogenic influence; however, detection and attribution using northern mid- to high-latitude data alone fails. In contrast to earlier work, the authors found that the magnitude of observed global SLP variability and change is consistent with simulations with the HadGEM1 model. Gillett and Stott (2009) analysed SLP changes from 1959 to 2009 and therefore also included the recent return of the NAO index to neutral and negative conditions (see Chap. 4, Box 4.1 and Fig. 4.1), which may reduce the discrepancy between simulations and observations. Nonetheless, there is still indication of an underestimation of the recent decrease in winter SLP in high northern latitudes. So far, it remains unclear to what extent changes in Northern Hemispheric SLP and NAO in particular are consistent with simulated anthropogenic signals.

\subsubsection{Near-Surface Wind and Storminess}

A variety of indices to characterise various aspects of storm climate can be found in the literature (see Chap. 4, Sect. 4.3). For the investigation of long-term changes, storminess indices based on pressure readings seem to provide the necessary homogeneous time series (see Krueger and von Storch 2011, for a discussion of related issues). In contrast, direct measurements of winds often suffer from inhomogeneity in the records related to site and instrument changes and build-up of surrounding areas (Trenberth et al. 2007; Lindenberg et al. 2012); they are thus not suited for attribution studies.

Wang et al. (2009) analysed geostrophic wind energy (derived from SLP) and ocean wave height across the Northern Hemisphere in a formal detection and attribution assessment and found a detectable external influence in winter (JFM). Their ensemble mean fingerprint includes increasing wind energy in north-western Europe. The models are able to reproduce the basic pattern, but simulated changes are smaller than the observed changes, and there is indication that models tend to underestimate internal variability compared with observations.

Using a different definition of storminess derived from pressure triangles, Matulla et al. (2008), Bärring and Fortuniak (2009) and Wang et al. (2011) confirmed the recent increase in storminess in northern Europe. Putting the recent increase in the historical context, however, Matulla et al. (2008) and Bärring and Fortuniak (2009) found little evidence of an emerging anthropogenic signal in the Baltic Sea area as similar increases have been observed in the past.
The long-term series of Wang et al. (2011) showed weak trends or a slight decrease in storminess in north-western Europe from 1875 to 2005. In contrast, Donat et al. (2011) identified a long-term increase in storminess in the twentieth-century reanalysis (20CR, Compo et al. 2011), but Krueger et al. (2013) showed that long-term changes in storminess in 20CR are not consistent with observations and may be an artefact of the temporally varying number of stations assimilated in the reanalysis.

Even though the recent observed changes in storminess in the North Atlantic and Northern Hemisphere have been detected, to what extent human influence has caused these changes is still a matter of debate as similar changes have been observed in the past. Therefore, more work is needed to reconcile differences between the various approaches. Evaluating climate models against the existing long observational series may offer additional insights into causes of recent and past changes in storminess and careful validation of the models' ability to reproduce low-frequency variability may help to strengthen future work on detection and attribution of changes in storminess.

\subsubsection{Hydrological Cycle}

Changes in the hydrological cycle are much more complex than changes to thermal quantities, as both thermodynamics and circulation changes play an important role in shaping changes in the hydrological cycle. The characteristics of the global response of the hydrological cycle can be summarised as follows. An absolute humidity increase of $7 \%$ per ${ }^{\circ} \mathrm{C}$ is expected, as a consequence of the increased water holding capacity of the atmosphere with rising temperature, and given relative humidity patterns stay approximately constant (Allen and Ingram 2002; Held and Soden 2006). The observed increase in global surface-specific humidity has been attributed to human influence (Willett et al. 2007). In the last decade, however, surface humidity has not increased further in concert with global temperature (Simmons et al. 2010), but levelled off after the 1997/98 El Niño. The authors speculated that surface humidity is instead dominated by ocean temperature.

In contrast to absolute humidity, precipitation increases by only $1-3 \%$ per ${ }^{\circ} \mathrm{C}$ (Allen and Ingram 2002; Held and Soden 2006; Wentz et al. 2007). This apparent discrepancy is resolved in models by decreasing convective mass flux and a slowdown of atmospheric circulation mainly in the tropics. Further consequences include an increase in the pattern of evaporation minus precipitation; that is, wet regions get wetter, dry regions get drier (Held and Soden 2006).

Global equilibrium precipitation depends on the perturbation of the tropospheric energy balance rather than the availability of moisture (Allen and Ingram 2002). Global 
precipitation is less sensitive to greenhouse gas forcing than shortwave forcing such as volcanic eruptions or solar irradiance changes. Increasing atmospheric greenhouse gas concentrations reduce the ability of the troposphere to radiate away latent heat from precipitation and thus counteract the precipitation increase due to surface warming (Allen and Ingram 2002). Therefore, shortwave forcing such as changes in volcanic aerosols should be easier to detect in global precipitation than the effect of the long-term increase of atmospheric greenhouse gas concentrations. Indeed, Lambert et al. $(2004,2005)$ detected an influence of the combined natural and anthropogenic forcing and concluded that most of the forced signal in global mean precipitation is due to natural forcing. These findings are in line with Gillett et al. (2004) who detected the influence of volcanic eruptions on the observed global land precipitation change over the twentieth century. It is important to note that the main process leading to precipitation changes is the radiative forcing leading to a perturbation of the tropospheric energy balance and not a potential effect of volcanic ash particles on cloud properties.

Recently, the influence of long-term forcing has also been detected. Zhang et al. (2007) found a detectable anthropogenic influence on recent observed trends in annual zonal mean precipitation. Their anthropogenic fingerprint features the well-known pattern of moistening in the tropics and high latitudes, and drying in the subtropics. The climate models, however, significantly underestimate the observed changes. The authors concluded that anthropogenic forcing contributed about $50-85 \%$ to the observed increase in precipitation in the northern mid-latitudes of $6.2 \mathrm{~mm}$ per decade. Noake et al. (2012) also detected external forcing in seasonal zonal mean precipitation over land in all seasons except boreal summer. Furthermore, they found that using relative anomalies reduces underestimation of observed precipitation trends. For northern Europe, Bhend (2010) detected external forcing on seasonal area-average precipitation in the Baltic Sea area. The analysis, however, also reveals that global climate models are not able to reproduce the observed variability in regional precipitation and the model-derived

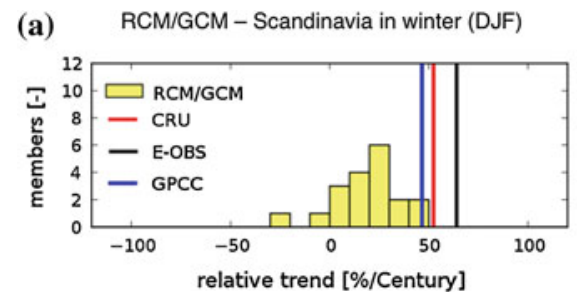

Fig. 23.3 Observed relative precipitation trends in winter (DJF, a) and summer (JJA, b) from 1961 to 2000 (vertical lines) along with the distribution of simulated precipitation trends in an ensemble of 19 regional climate model simulations (yellow bars, updated from van Haren et al. 2012). In contrast to the original manuscript, the observed trends are derived from the precipitation dataset of the Global signals have to be inflated significantly to best fit the observations. Therefore, the confidence in this detection finding is low.

Bhend and von Storch (2008) found that the pattern of recent observed changes in winter precipitation is consistent with the anthropogenic signal-mainly greenhouse gasesderived from regional climate model simulations. The magnitude of the change, however, is much smaller in the simulations compared with the observations in line with other studies and the discussion about understanding regional circulation changes. Van Haren et al. (2012) also identified significant discrepancies between observed and simulated precipitation changes in Europe in winter (Fig. 23.3a). They further established that biases in simulated sea-surface temperature (SST) and circulation changes are the main causes of the inconsistencies between simulated and observed changes in regional precipitation in winter. In summer, the simulated precipitation changes correspond well with the observations (Fig. 23.3b).

Min et al. (2008a) found a detectable human influence on Arctic moistening. Their analysis indicates that anthropogenic forcing has led to an increase in precipitation over land north of $55^{\circ} \mathrm{N}$ (including the northern Baltic Sea area), whereas natural forcing has led to a decrease in precipitation from 1950 to 1999 . Their analysis further suggests that the simulated changes underestimate the observed moistening considerably, and their best-guess anthropogenic signal has to be scaled up significantly to match the observed change; moreover, the simulated internal variability is not consistent with the observed residual variability, which indicates that the models underestimate both forced and internal variability in precipitation. If AO-related variability is removed from the observations, simulated changes including all forcing mechanisms and the simulated variability are consistent with the observations.

Min et al. (2009) investigated potential detectability of change in extreme precipitation in simulations. They found that detectability of changes in extreme precipitation in Europe is low for the twentieth century. Recently, Min et al.

(b) RCM/GCM - Scandinavia in summer (JJA)

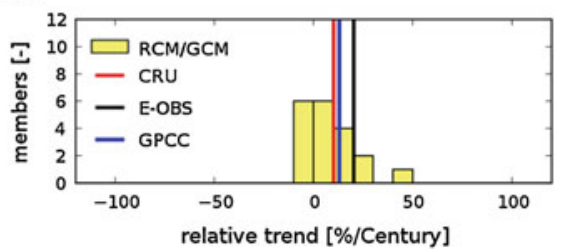

Precipitation Climatology Centre (GPCC) and the updated CRU_TS3.10.01 and E-OBS v7.0 datasets. The ensemble of regional climate model simulations includes different regional/global model combinations (van Haren et al. 2012). Most of the models fail to reproduce the observed increase in precipitation in winter 
(2011) detected an anthropogenic influence on annual maxima of daily and five-day consecutive precipitation changes from 1951 to 1999 over land in the northern midlatitudes, but the signal is not detectable for Eurasia alone. As with mean precipitation, their results suggest that models underestimate the observed change.

In climates with intermittent snow cover, such as the Baltic Sea catchment, run-off regimes change with temperature. Earlier snowmelt due to warming leads to peak river run-off earlier in the year. Recent studies demonstrate a detectable anthropogenic influence on regional run-off for the north-western USA (Barnett et al. 2008; Hidalgo et al. 2009). However, Hansson et al. (2011) concluded that recent changes in river run-off into the Baltic Sea are not exceptional compared to changes over the past 500 years according to their reconstruction of river run-off. A formal attribution analysis for river run-off in Europe, however, is not available so far. The above studies and the often long observational records of river run-off illustrate the potential for regional attribution. On the other hand, the complex processes involved in run-off generation and human influence through land-use change in the catchment area, withdrawal and regulation are major challenges when trying to attribute run-off changes.

There is some evidence for a human influence on run-off from global and continental studies. Milly et al. (2005) illustrated that observed changes in run-off around the world are significantly correlated with simulated changes due to anthropogenic forcing - thus indicating that the global pattern of observed streamflow changes during the twentieth century is unlikely due to internal variability alone. Stahl et al. (2010) and Wilson et al. (2010) concluded that streamflow changes in near-natural catchments in northern Europe in winter and spring are congruent with expected streamflow changes due to human influence. Furthermore, Wilson et al. (2010) found that recent streamflow changes are in line with expected future changes in seasons when the temperature signal dominates (winter and spring). In contrast, the expected future increase in summer and autumn streamflow due to increasing precipitation and the spatial characteristics of the human signal in streamflow do not manifest in recent observed changes.

A vast body of literature examines the proximate causes of interannual snow cover variability. Large-scale atmospheric circulation - and the NAO in particular - have been shown to be a strong determining factor of changing snow conditions in the Baltic Sea region. The large-scale circulation affects the extent of European snow cover (Henderson and Leathers 2010), snow amounts (Kohler et al. 2006; Falarz 2007; Popova 2007; Bednorz and Wibig 2008), the occurrence of heavy snowfall (Bednorz and Wibig 2008) and snow cover duration (Klavins et al. 2009). However, formal assessments of the ultimate causes, such as increasing atmospheric greenhouse gas concentrations, for changes in snow conditions are still rare. A first formal detection and attribution assessment has been carried out for the northwestern USA identifying a human influence on the decline in snowpack measured as the snow-water equivalent in spring (Pierce et al. 2008). For the Baltic Sea area, no such analysis is available so far.

The response of snow to observed recent warming and increasing precipitation in winter is non-trivial and depends on various factors such as the climatology and, therefore, varies with elevation and continentality (Räisänen 2008). Furthermore, not all snow properties will be equally sensitive to warming. Snow cover duration has been identified to be most sensitive to warming (Brown and Mote 2009), and earlier snow melt and decreasing snow cover duration have been found in the Baltic Sea area (see Chap. 6; Brown and Mote 2009; Choi et al. 2010). These changes are in line with the expected response to anthropogenic forcing. On the other hand, changes in maximum snow depth or maximum snowwater equivalent are very variable over the Baltic Sea area (see Chap. 6; Liston and Hiemstra 2011), which is due to the strong interannual variability; an anthropogenic signal may not have emerged yet (Räisänen and Eklund 2011).

\section{Box 23.1 Event attribution: proximate versus ultimate causes}

When identifying causes of individual weather- and climate-related extreme events, typically two distinct approaches are taken. Often, attempts are made to identify proximate causes such as the large-scale circulation or specific sea-surface temperature patterns favouring the occurrence and intensity of the event under consideration. For example, the NAO and the El Niño/Southern Oscillation (ENSO) have been identified as key players for the cold and snowy winter of 2009/2010 in Europe (Cohen et al. 2010; Seager et al. 2010). In contrast, there are very few studies attempting to identify the contribution of external forcing (ultimate causes) to extreme events (Stott et al. 2004; Pall et al. 2011). In the context of the cold winter of 2009/2010 in Europe, Cattiaux et al. (2010) concluded that the winter was not exceptional compared to past winters and was also considerably less cold than expected due to the record-breaking circulation indices (NAO and blocking) alone. This illustrates the combined effect of circulation anomalies 
(proximate causes) and background warming (here a proxy for external forcing causing global warming). In this case, it could be concluded that winter 2009/2010 was a cold winter despite global warming and an exceptionally cold winter given global warming.

Identified proximate causes of extreme events are often perceived as contradicting a potential human influence. This is generally not the case. An extreme event is by definition rare and thus will only occur under particular conditions. Therefore, a large fraction of the intensity of an extreme event may be due to internal variability or, equivalently, an extreme event may not occur due to external forcing alone. This gave rise to the widespread public belief that it is not possible to attribute a single event to climate change. External forcing, however, can have a strong influence on the frequency of occurrence of extreme events as events that are exceedingly rare (or common) in the pre-industrial climate may become more (less) frequent due to external forcing.

The subtleties and importance of clarity in relation to the question asked in event attribution are illustrated by the case of the Russian heat wave of 2010. Dole et al. (2011) identified atmospheric blocking and thus natural internal variability as the main contributor to the intensity of the heat wave. In contrast, Rahmstorf and Coumou (2011) concluded that with a probability of $80 \%$ the Russian heat wave would not have occurred without the recent large-scale warming (most of which is attributable to human influence). The apparent contradiction is resolved by Otto et al. (2012), pointing out that whereas anthropogenic forcing only contributed relatively little to the intensity of the heat wave, it increased the estimated return time of such an event considerably (see Fig. 23.4).

In addition to the challenging distinction between the roles of proximate and ultimate causes, attribution of extreme events may be subject to selection bias. This selection bias relates to the fact that it is usually time series with recent extreme events that are studied (see for example Stott et al. 2004 and Coumou and Rahmstorf 2012). Selection biases could be avoided by using operationalised systems that routinely assess the attribution question for a set of pre-specified indices.

Attribution of extreme events (and climate change in general) to both proximate and ultimate causes is important to improve understanding of the climate system and to enhance predictability of extreme events. The communication of often seemingly contradictory findings arising from the two different approaches, however, will remain challenging.

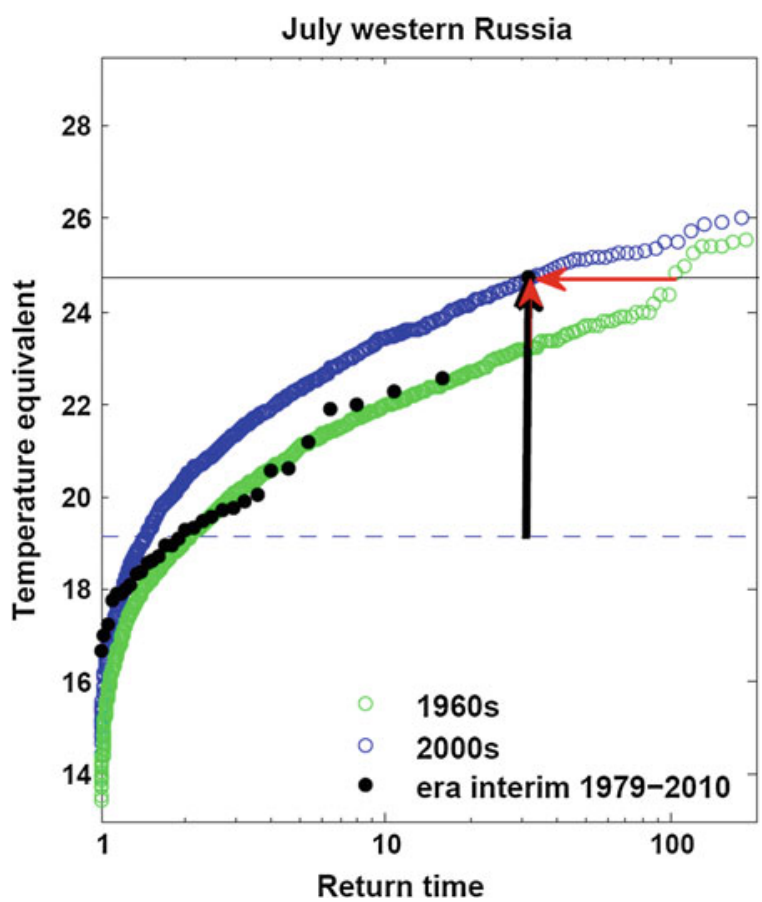

Fig. 23.4 Return periods of an index describing combined temperature and geopotential height conditions in the model for the 1960s (green) and the 2000s (blue) and in ERA-Interim for 1979-2010 (black). The vertical black arrow shows the anomaly of the Russian heat wave in 2010 (black horizontal line) compared to the July mean temperatures of the 1960s (dashed line). The vertical red arrow indicates the increase in the magnitude of the heat wave due to the shift of the distribution, whereas the horizontal red arrow shows the change in the return period (reproduced from Otto et al. 2012)

\subsection{Causes of Change in the Baltic Sea}

The human influence on ocean heat content has been detected (Barnett et al. 2001), and changes in all of the major ocean basins are found to be different from internal variability (Pierce et al. 2006; Palmer et al. 2009). Due to the complex and small-scale bathymetry of the Baltic Sea, however, the available atmosphere-ocean general circulation model (AOGCM) simulations cannot be used for detection and attribution studies in this area. Therefore, no formal detection and attribution assessment for the Baltic Sea is yet available.

Hansson and Omstedt (2008) investigated maximum ice extent and horizontally and vertically integrated temperature in the Baltic Sea using the PROBE-Baltic model. They used observations and climate proxy reconstructions as boundary conditions for their model and concluded that the recent warming and recent rate of warming does not stand out in the context of the past 500 years and thus cannot be detected. Furthermore, they do not recommend using GCM data as boundary conditions for their ocean model, thus inhibiting a formal detection and attribution approach. 
Salinity in major ocean basins has been used to infer changes in freshwater run-off and precipitation (Hegerl et al. 2007b). Temporal variability of the salinity in the Baltic Sea, however, is strongly dependent on Major Baltic Inflow events of highly saline water from the North Sea (Matthäus et al. 2008). These events in turn depend on the large-scale circulation and on the salinity of the Baltic Sea (among other factors). Meier and Kauker (2003) found, based on hindcasts of Baltic Sea salinity, that salinity changes in the Baltic Sea are linked partly to changes in freshwater influx and precipitation and partly to changes in the large-scale atmospheric circulation. Due to the coupling of Baltic Sea salinity with the salinity of the North Sea and the dependence of the exchange on properties in both basins, attribution of changes in Baltic Sea salinity may only be partially achieved.

As the density of water decreases (and thus its volume increases) with increasing temperature, global sea level generally rises with increasing ocean heat content (among other factors, see Chap. 9, Sect. 9.3). Global sea level changes since 1960 agree well with simulations including anthropogenic and volcanic forcing (Domingues et al. 2008). The regional pattern of sea level rise, however, is only partly understood. Changes in sea level in the Baltic Sea have been shown to vary in concert with circulation and precipitation changes (Hünicke and Zorita 2006). The contribution of these regional effects to sea level in the Baltic Sea are of the same order of magnitude as the global sea level rise (Hünicke 2010) and thus have to be accounted for in future detection and attribution studies.

Finally, changes in sea ice are to be expected with global warming. Arctic sea ice changes have been attributed to human influences (Min et al. 2008b) and are in fact attributable since 1992. Sea ice formation in the Baltic Sea, however, is hardly comparable to Arctic sea ice, as the brackish water, the complex bathymetry and the limited extent of the Baltic Sea lead to distinct features of ice formation. The annual maximum Baltic Sea ice extent is decreasing, and from 1987 to 2009, all winters have been average or below average with regard to maximum ice extent (Vihma and Haapala 2009). The general tendency towards milder winters is masked by considerable interannual variability; the most recent winters of 2009/2010 and 2010/ 2011, for example, have been judged to be severe winters by the Swedish Meteorological and Hydrological Institute (SMHI). The long time series of ice extent and break-up dates available across the Baltic Sea would lend itself to attribution assessments (see Chap. 8). A formal detection and attribution assessment of Baltic Sea ice, however, is not available so far.

\subsection{Causes of Climate Change Impacts}

Attributing climate change impacts to causes is often complicated by the multitude of confounding factors acting on the system. Changes in marine biodiversity, for example, have been linked to climate (Hiddink and Coleby 2011), and ecosystem changes have been linked to atmospheric and direct human interference with the system (Moellmann et al. 2009). As in other attribution assessments, these linkages are based on multivariate linear regression and the results can be strongly dependent on the number of potential drivers included in the analysis. While statistical approaches provide readily available tools to explore relationships in complex systems, avoiding selection bias is crucial to avoid misattribution in systems with a multitude of potential causes.

There is a multitude of approaches for attributing causes to observed changes in climate change impacts. Hegerl et al. (2010) suggested making the distinction between four different approaches:

1. Single-step attribution to external forcing These methods assess the influence of external forcing onto an observed quantity with an integrated modelling system that explicitly simulates the effect of all plausible drivers on the respective variable.

2. Multi-step attribution to external forcing consists of several independent but linked attribution assessments. First, changes in impacts or changes in a biological system are attributed to changes in climatic conditions. In a second step, the changes in climatic conditions are attributed to changes in external forcing. The two independent assessments and their respective uncertainties are then combined to describe the resulting effect of the external forcing on the target quantity. Such an approach may be advantageous if modelling systems are incapable of faithfully reproducing the link between the target quantity and the climatic conditions.

3. Associative pattern attribution to external forcing is a 'meta-analysis' to characterise the sensitivity of systems to changes in external forcing based on correspondence or disagreement in the relative response across a large number of studies (in different regions and/or systems).

4. Attribution to a change in climatic conditions (but not explicitly to changes in external forcing) can be the last step in a multi-step attribution analysis but is more often found as a stand-alone analysis (see Box 23.1).

An example of an associative pattern attribution analysis is the study of Rosenzweig et al. (2008). Based on a compilation of significant findings from a wide range of analyses of change in physical and biological systems, the authors 
calculated the fraction of the findings that are consistent with the local warming. For Europe, they found that $94 \%$ of the studies investigating change in the physical systems and $90 \%$ of the studies on changes in the biological systems find changes that are consistent with the observed warming. While such an approach is valuable in providing an overview of findings across systems, there is the potential danger of sampling issues influencing the results.

If process models of the system are available, the uncertainties in the response to changes in the various drivers (climate and other) can be fully explored. Such an end-to-end attribution analysis, however, is so far not available for the Baltic Sea area.

\subsection{Conclusion}

There is a wealth of evidence documenting human influence on the observed warming globally, on all continents and in many subcontinental regions. For the last assessment report (BACC Author Team 2008), no formal assessments on the potential causes of the observed climate change in the Baltic Sea area had been available. Since then, a few such studies have been published. There is some indication of an emerging anthropogenic signal, which is detectable in thermal quantities such as seasonal temperature, but evidence for detection of changes in non-thermal quantities such as circulation and precipitation is weak.

Although human influence (mainly increasing concentrations of greenhouse gases) has been identified as a cause of the recent warming in the Baltic Sea area, there are caveats. The causes of recent circulation changes in the Euro-Atlantic sector are not yet understood, and therefore, attribution of changes especially in winter and spring are to be treated with caution. Furthermore, quantification of the contribution of individual forcings has not been accomplished. Better understanding of the regional effects of natural forcings and the effect of anthropogenic aerosols (see Chap. 24) may help to achieve quantified attribution statements. Finally, detection and attribution efforts are often subject to selection and publication biases. That is, time series with 'interesting' behaviour are preferentially studied and positive findings (of a detectable anthropogenic effect) are more likely to be published. To avoid these biases, systems to routinely issue statements on the contribution of external forcing to the observed climate across a range of pre-specified variables and regions are needed.

Open Access This chapter is distributed under the terms of the Creative Commons Attribution Noncommercial License, which permits any noncommercial use, distribution, and reproduction in any medium, provided the original author(s) and source are credited.

\section{References}

Allen MR, Ingram WJ (2002) Constraints on future changes in climate and the hydrologic cycle. Nature 419:224-228

BACC Author Team (2008) Assessment of Climate Change for the Baltic Sea Basin. Regional Climate Studies, Springer-Verlag, Berlin, Heidelberg

Barnett TP, Pierce DW, Schnur R (2001) Detection of anthropogenic climate change in the world's oceans. Science 292:270-274

Barnett TP, Pierce DW, Hidalgo HG, Bonfils C, Santer BD, Das T, Bala G, Wood AW, Nozawa T, Mirin AA, Cayan DR, Dettinger MD (2008) Human-induced changes in the hydrology of the western United States. Science 319:1080-1083

Bärring L, Fortuniak K (2009) Multi-indices analysis of southern Scandinavian storminess 1780-2005 and links to interdecadal variations in the NW Europe-North Sea region. Int J Climatol 29:373-384

Bednorz E, Wibig J (2008) Snow depth in Eastern Europe in relation to circulation patterns. Ann Glaciol 48:135-149

Bhend J (2010) Detection of an anthropogenic influence on the observed changes in near-surface temperature and precipitation in northern Europe. GKSS Report 2010/3. GKSS Research Centre, Geesthacht, Germany

Bhend J, von Storch H (2008) Consistency of observed winter precipitation trends in northern Europe with regional climate change projections. Clim Dynam 31:17-28

Bhend J, von Storch H (2009) Is greenhouse gas forcing a plausible explanation for the observed warming in the Baltic Sea catchment area? Boreal Environ Res 14:81-88

Brown RD, Mote PW (2009) The response of northern hemisphere snow cover to a changing climate. J Clim 22:2124-2145

Cattiaux J, Vautard R, Cassou C, Yiou P, Masson-Delmotte V, Codron F (2010) Winter 2010 in Europe: A cold extreme in a warming climate. Geophys Res Lett 37:L20704. doi: 10.1029/2010GL044613

Choi G, Robinson DA, Kang S (2010) Changing northern hemisphere snow seasons. J Clim 23:5305-5310

Christidis N, Stott PA, Brown S, Hegerl GC, Caesar J (2005) Detection of changes in temperature extremes during the second half of the 20th century. Geophys Res Lett 32:L20716. doi:10.1029/ 2005GL023885

Christidis N, Stott PA, Brown S, Karoly DJ, Caesar J (2007) Human contribution to the lengthening of the growing season during 195099. J Clim 20:5441-5454

Christidis N, Stott PA, Jones GS, Shiogama H, Nozawa T, Luterbacher J (2010a) Human activity and anomalously warm seasons in Europe. Int J Climatol 32:225-239

Christidis N, Stott PA, Zwiers FW, Shiogama H, Nozawa T (2010b) Probabilistic estimates of recent changes in temperature: a multiscale attribution analysis. Clim Dynam 34:1139-1156

Christidis N, Stott PA, Brown SJ (2011) The role of human activity in the recent warming of extremely warm daytime temperatures. J Clim 24:1922-1930

Cohen J, Foster J, Barlow M, Saito K, Jones J (2010) Winter 20092010: A case study of an extreme arctic oscillation event. Geophys Res Lett 37:L17707. doi: 10.1029/2010GL044256

Compo GP, Whitaker JS, Sardeshmukh PD, Matsui N, Allan RJ, Yin X, Gleason BE, Vose RS, Rutledge G, Bessemoulin P, Brönnimann S, Brunet M, Crouthamel RI, Grant AN, Groisman PY, Jones PD, Kruk MC, Kruger AC, Marshall GJ, Maugeri M, Mok HY, Nordli Ã, Ross TF, Trigo RM, Wang XL, Woodruff SD, Worley SJ (2011) The twentieth century reanalysis project. Q J Roy Meteor Soc 137:1-28.

Coumou D, Rahmstorf S (2012) A decade of weather extremes. Nat Clim Change 2:491-496 
Dole R, Hoerling M, Perlwitz J, Eischeid J, Pegion P, Zhang T, Quan $\mathrm{X}-\mathrm{W}, \mathrm{Xu}$ T, Murray D (2011) Was there a basis for anticipating the 2010 Russian heat wave? Geophys Res Lett 38:L06702. doi: 10. 1029/2010GL046582

Domingues CM, Church JA, White NJ, Gleckler PJ, Wijffels SE, Barker PM, Dunn JR (2008) Improved estimates of upper-ocean warming and multi-decadal sea-level rise. Nature 453:1090-1093

Donat MG, Renggli D, Wild S, Alexander LV, Leckebusch GC, Ulbrich U (2011) Reanalysis suggests long-term upward trends in European storminess since 1871. Geophys Res Lett 38:L14703. doi: 10.1029/2011GL047995

Falarz M (2007) Snow cover variability in Poland in relation to the macro- and mesoscale atmospheric circulation in the twentieth century. Int J Climatol 27:2069-2081

Flanner MG, Zender CS, Hess PG, Mahowald NM, Painter TH, Ramanathan V, Rasch PJ (2009) Springtime warming and reduced snow cover from carbonaceous particles. Atmos Chem Phys 9:2481-2497

Gillett NP (2005) Northern hemisphere circulation. Nature 437:496-496

Gillett NP, Stott PA (2009) Attribution of anthropogenic influence on seasonal sea level pressure. Geophys Res Lett 36:L23709. doi: 10. 1029/2009GL041269

Gillett NP, Hegerl GC, Allen MR, Stott PA (2000) Implications of changes in the northern hemisphere circulation for the detection of anthropogenic climate change. Geophys Res Lett 27:993-996

Gillett NP, Weaver AJ, Zwiers FW, Wehner MF (2004) Detection of volcanic influence on global precipitation. Geophys Res Lett 31: L12217. doi:10.1029/2004GL020044

Gillett NP, Allan RJ, Ansell TJ (2005) Detection of external influence on sea level pressure with a multi-model ensemble. Geophys ResLett 32:L19714. doi: 10.1029/2005GL023640

Gillett NP, Stone DA, Stott PA, Nozawa T, Karpechko AY, Heger GC, Wehner MF, Jones PD (2008) Attribution of polar warming to human influence. Nat Geosci 1:750-754

Hansson D, Omstedt A (2008) Modelling the Baltic Sea ocean climate on centennial time scale: temperature and sea ice. Clim Dynam 30:763-778

Hansson D, Eriksson C, Omstedt A, Chen D (2011) Reconstruction of river runoff to the Baltic Sea, AD 1500-1995. Int J Climatol 31:696-703

Hegerl GC, Hasselmann K, Cubasch U, Mitchell JFB, Roeckner E, Voss R, Waszkewitz J (1997) Multi-fingerprint detection and attribution analysis of greenhouse gas, greenhouse gas-plus-aerosol and solar forced climate change. Clim Dynam 13:613-634

Hegerl GC, Zwiers FW, Braconnot P, Gillett NP, Luo Y, Marengo Orsini JA, Nicholls N, Penner JE, Stott PA (2007a) Understanding and attributing climate change. In: Climate Change 2007: The Physical Science Basis. Contribution of Working Group I to the Fourth Assessment Report of the Intergovernmental Panel on Climate Change. Cambridge University Press, Cambridge, UK and New York, USA, p 663-745

Hegerl GC, Crowley TJ, Allen M, Hyde WT, Pollack HN, Smerdon J, Zorita E (2007b) Detection of human influence on a new, validated 1500-year temperature reconstruction. J Clim 20:650-666

Hegerl GC, Hoegh-Guldberg O, Casassa G, Hoerling MP, Kovats RS, Parmesan C, Pierce DW, Stott PA (2010) Good practice guidance paper on detection and attribution related to anthropogenic climate change. In: Stocker TF, Field CB, Qin D, Barros V, Plattner G-K, Tignor M, Midgley PM, Ebi KL (eds), Meeting Report of the Intergovernmental Panel on Climate Change Expert Meeting on Detection and Attribution of Anthropogenic Climate Change, IPCC Working Group I Technical Support Unit, University of Bern, Switzerland
Hegerl G, Luterbacher J, Gonzalez-Rouco F, Tett SFB, Crowley T, Xoplaki E (2011) Influence of human and natural forcing on European seasonal temperatures. Nat Geosci 4:99-103

Held IM, Soden BJ (2006) Robust responses of the hydrological cycle to global warming. J Clim 19:5686-5699

Henderson GR, Leathers DJ (2010) European snow cover extent variability and associations with atmospheric forcings. Int $\mathrm{J}$ Climatol 30:1440-1451

Hidalgo HG, Das T, Dettinger MD, Cayan DR, Pierce DW, Barnett TP, Bala G, Mirin A, Wood AW, Bonfils C, Santer BD, Nozawa T (2009) Detection and attribution of streamflow timing changes to climate change in the western United States. J Clim 22:3838-3855

Hiddink JG, Coleby C (2011) What is the effect of climate change on marine fish biodiversity in an area of low connectivity, the Baltic Sea? Global Ecol Biogeogr 21:637-646

Hünicke B (2010) Contribution of regional climate drivers to future winter sea-level changes in the Baltic Sea estimated by statistical methods and simulations of climate models. Int J Earth Sci 99:17211730

Hünicke B, Zorita E (2006) Influence of temperature and precipitation on decadal Baltic Sea level variations in the 20th century. Tellus A $58: 141-153$

Hurrell J, Kushnir Y, Ottersen G, Visbeck M (2003). An overview of the North Atlantic Oscillation. In: The North Atlantic Oscillation: Climatic Significance and Environmental Impact. American Geophysical Union, Washington, DC, p 1-35

Jones GS, Stott PA, Christidis N (2008) Human contribution to rapidly increasing frequency of very warm northern hemisphere summers. J Geophys Res Atmos 113:D2. doi: 10.1029/2007JD008914

Karoly DJ, Wu QG (2005) Detection of regional surface temperature trends. J Clim 18:4337-4343

Kiktev D, Sexton D, Alexander L, Folland C (2003) Comparison of modeled and observed trends in indices of daily climate extremes. J Clim 16:3560-3571

Klavins M, Briede A, Rodinov V (2009) Long term changes in ice and discharge regime of rivers in the Baltic region in relation to climatic variability. Climatic Change 95:485-498

Kohler J, Brandt O, Johansson M, Callaghan T (2006) A long-term arctic snow depth record from Abisko, northern Sweden, 19132004. Polar Res 25:91-113

Krueger O, von Storch H (2011) Evaluation of an air pressure-based proxy for storm activity. J Clim 24:2612-2619

Krueger O, Schenk F, Feser F, Weisse R (2013) Inconsistencies between long-term rends in storminess derived from the 20CR Reanalysis and observations. J Clim 26:868-874

Lambert FH, Stott PA, Allen MR, Palmer MA (2004) Detection and attribution of changes in 20th century land precipitation. Geophys Res Lett 31:L10203

Lambert FH, Gillett NP, Stone DA, Huntingford C (2005) Attribution studies of observed land precipitation changes with nine coupled models. Geophys Res Lett 32:L18704. doi: 10.1029/ 2005GL023654

Lindenberg J, Mengelkamp H-T, Rosenhagen G (2012) Representativity of near surface wind measurements from coastal stations at the German Bight. Meteorol Z 21:99-106

Liston GE, Hiemstra CA (2011) The changing cryosphere: Pan-arctic snow trends (1979-2009). J Clim 24:5691-5712

Masson D, Knutti R (2011) Spatial-scale dependence of climate model performance in the CMIP3 ensemble. J Clim 24:2680-2692

Matthäus W, Nehring D, Feistel R, Nausch G, Mohrholz V, Lass H-U (2008) The inflow of highly saline water into the Baltic Sea. In: Feistel R, Nausch G, Wasmund N (eds), State and Evolution of the Baltic Sea, 1952-2005. A Detailed 50-Year Survey of Meteorology 
and Climate, Physics, Chemistry, Biology, and Marine Environment. John Wiley \& Sons, p 265-309

Matulla C, Schoner W, Alexandersson H, von Storch H, Wang XL (2008) European storminess: late nineteenth century to present. Clim Dynam 31:125-130

Meier HEM, Kauker F (2003) Modeling decadal variability of the Baltic Sea. Part 2: The role of freshwater inflow and large-scale atmospheric circulation for salinity. J Geophys Res 108:3368-3377

Miller RL, Schmidt GA, Shindell DT (2006) Forced annular variations in the 20th century Intergovernmental Panel on Climate Change Fourth Assessment Report models. J Geophys Res Atmos 111: D18101. doi: 10.1029/2005JD006323

Milly PCD, Dunne KA, Vecchia AV (2005) Global pattern of trends in streamflow and water availability in a changing climate. Nature 438:347-350

Min SK, Hense A (2007a) A Bayesian assessment of climate change using multimodel ensembles. Part II: Regional and seasonal mean surface temperatures. J Clim 20:2769-2790

Min S-K, Hense A (2007b) Hierarchical evaluation of IPCC AR4 coupled climate models with systematic consideration of model uncertainties. Clim Dynam 29:853-868

Min SK, Zhang XB, Zwiers F (2008a) Human-induced arctic moistening. Science 320:518-520

Min SK, Zhang XB, Zwiers FW, Agnew T (2008b) Human influence on arctic sea ice detectable from early 1990s onwards. Geophys Res Lett 35:L21701. doi: 10.1029/2008GL035725

Min SK, Zhang XB, Zwiers FW, Friederichs P, Hense A (2009) Signal detectability in extreme precipitation changes assessed from twentieth century climate simulations. Clim Dynam 32:95-111

Min S-K, Zhang X, Zwiers FW, Hegerl GC (2011) Human contribution to more-intense precipitation extremes. Nature 470:378-381

Moellmann C, Diekmann R, Mueller-Karulis B, Kornilovs G, Plikshs M, Axe P (2009) Reorganization of a large marine ecosystem due to atmospheric and anthropogenic pressure: a discontinuous regime shift in the central Baltic Sea. Global Change Biol 15:1377-1393

Morak S, Hegerl GC, Kenyon J (2011) Detectable regional changes in the number of warm nights. Geophys Res Lett 38:L17703. doi: 10. 1029/2011GL048531

Noake K, Polson D, Hegerl G, Zhang X (2012) Changes in seasonal land precipitation during the latter twentieth-century. Geophys Res Lett 39:L03706. doi: 10.1029/2011GL050405

Otto FEL, Massey N, van Oldenborgh GJ, Jones RG, Allen MR (2012) Reconciling two approaches to attribution of the 2010 Russian heat wave. Geophys Res Lett 39:L04702. doi: 10.1029/2011GL050422

Pall P, Aina T, Stone DA, Stott PA, Nozawa T, Hilberts AGJ, Lohmann D, Allen MR (2011) Anthropogenic greenhouse gas contribution to flood risk in England and Wales in autumn 2000. Nature 470:382385

Palmer MD, Good SA, Haines K, Rayner NA, Stott PA (2009) A new perspective on warming of the global oceans. Geophys Res Lett 36: L20709. doi: 10.1029/2009GL039491

Pierce DW, Barnett TP, AchutaRao KM, Gleckler PJ, Gregory JM, Washington WM (2006) Anthropogenic warming of the oceans: Observations and model results. J Clim 19:1873-1900

Pierce DW, Barnett TP, Hidalgo HG, Das T, Bonfils C, Santer BD, Bala G, Dettinger MD, Cayan DR, Mirin A, Wood AW, Nozawa T (2008) Attribution of declining western U.S. snowpack to human effects. J Clim 21:6425-6444

Popova V (2007) Winter snow depth variability over northern Eurasia in relation to recent atmospheric circulation changes. Int J Climatol 27:1721-1733

Rahmstorf S, Coumou D (2011) Increase of extreme events in a warming world. Proc Nat Acad Sci 108:17905-17909
Räisänen J (2008) Warmer climate: less or more snow? Clim Dynam 30:307-319

Räisänen J, Eklund J (2011) 21st century changes in snow climate in northern Europe: a high-resolution view from ensembles regional climate models. Clim Dynam 38:2575-2591

Rosenzweig C, Karoly D, Vicarelli M, Neofotis P, Wu Q, Casassa G, Menzel A, Root TL, Estrella N, Seguin B, Tryjanowski P, Liu C, Rawlins S, Imeson A (2008) Attributing physical and biological impacts to anthropogenic climate change. Nature 453:353-357

Seager R, Kushnir Y, Nakamura J, Ting M, Naik N (2010) Northern hemisphere winter snow anomalies: ENSO, NAO and the winter of 2009/10. Geophys Res Lett 37:L14703. doi: 10.1029/ 2010GL043830

Simmons AJ, Willett KM, Jones PD, Thorne PW, Dee DP (2010) Lowfrequency variations in surface atmospheric humidity, temperature, and precipitation: Inferences from reanalyses and monthly gridded observational data sets. J Geophys Res Atmos 115:D01110. doi: 10. 1029/2009JD012442

Stahl K, Hisdal H, Hannaford J, Tallaksen LM, van Lanen HAJ, Sauquet E, Demuth S, Fendekova M, Jodar J (2010) Streamflow trends in Europe: evidence from a dataset of near-natural catchments. Hydrol Earth Syst Sci 14:2367-2382

Stott PA (2003) Attribution of regional-scale temperature changes to anthropogenic and natural causes. Geophys Res Lett 30:1728. doi: 10.1029/2003GL017324

Stott PA, Tett SFB (1998) Scale-dependent detection of climate change. J Clim 11:3282-3294

Stott PA, Stone DA, Allen MR (2004) Human contribution to the European heatwave of 2003. Nature 432:610-614

Stott PA, Gillett NP, Hegerl GC, Karoly DJ, Stone DA, XueBin Z, Zwiers F (2010) Detection and attribution of climate change: a regional perspective. WIREs Clim Change 1:192-211

Stott PA, Jones GS, Christidis N, Zwiers FW, Hegerl G, Shiogama H (2011) Single-step attribution of increasing frequencies of very warm regional temperatures to human influence. Atmos Sci Lett 12:220-227

Taylor KE, Stouffer RJ, Meehl GA (2011) An overview of CMIP5 and the experiment design. Bull Am Meteorol Soc 93:485-498

Trenberth K, Jones P, Ambenje P, Bojariu R, Easterling D, Tank AK, Parker D, Rahimzadeh F, Renwick J, Rusticucci M, Soden B, Zhai P (2007) Observations: surface and atmospheric climate change. In: Climate Change 2007: The Physical Science Basis. Cambridge University Press, Cambridge, UK and New York, USA, p 235-336 van Haren R, van Oldenborgh G, Lenderink G, Collins M, Hazeleger W (2012) SST and circulation trend biases cause an underestimation of European precipitation trends. Clim Dynam 40:1-20

van Oldenborgh GJ, Drijfhout S, van Ulden A, Haarsma R, Sterl A, Severijns C, Hazeleger W, Dijkstra H (2009) Western Europe is warming much faster than expected. Clim Past 5:1-12

Vihma T, Haapala J (2009) Geophysics of sea ice in the Baltic Sea: A review. Progr Oceanogr 80:129-148

Wang XLL, Swail VR, Zwiers FW, Zhang XB, Feng Y (2009) Detection of external influence on trends of atmospheric storminess and northern oceans wave heights. Clim Dynam 32:189-203

Wang X, Wan H, Zwiers F, Swail V, Compo G, Allan R, Vose R, Jourdain S, Yin X (2011) Trends and low-frequency variability of storminess over Western Europe, 1878-2007. Clim Dynam 37:2355-2371

Wentz FJ, Ricciardulli L, Hilburn K, Mears C (2007) How much more rain will global warming bring? Science 317:233-235

Willett KM, Gillett NP, Jones PD, Thorne PW (2007) Attribution of observed surface humidity changes to human influence. Nature 449:710-712 
Wilson D, Hisdal H, Lawrence D (2010) Has streamflow changed in the Nordic countries? Recent trends and comparisons to hydrological projections. J Hydrol 394:334-346

Woollings T (2010) Dynamical influences on European climate: an uncertain future. Phil Trans Math Phys Eng Sci 368:3733-3756

Wu Q (2010) Associations of diurnal temperature range change with the leading climate variability modes during the northern hemisphere wintertime and their implication on the detection of regional climate trends. J Geophys Res 115:D19101. doi: 10.1029/2010JD014026

Wu Q, Karoly DJ (2007) Implications of changes in the atmospheric circulation on the detection of regional surface air temperature trends. Geophys Res Lett 34:L08703. doi: 10.1029/2006GL028502
Zhang XB, Zwiers FW, Hegerl GC, Lambert FH, Gillett NP, Solomon S, Stott PA, Nozawa T (2007) Detection of human influence on twentieth-century precipitation trends. Nature 448: 461-465

Zorita E, Stocker TF, von Storch H (2008) How unusual is the recent series of warm years? Geophys Res Lett 35:L24706. doi:10.1029/ 2008GL036228

Zwiers FW, Zhang XB (2003) Toward regional-scale climate change detection. J Clim 16:793-797

Zwiers FW, Zhang X, Feng Y (2010) Anthropogenic influence on long return period daily temperature extremes at regional scales. J Clim 24:881-892 